\title{
Prevalencia de placa dentobacteriana y caries dental en el primer molar permanente en una población escolar del sur de la Ciudad de México
}

\author{
Olga Taboada-Aranza ${ }^{1 *}$ y Karen Rodríguez-Nieto ${ }^{2}$ \\ ${ }^{1}$ FES Zaragoza, Universidad Nacional Autónoma de México; ${ }^{2}$ Práctica privada. Ciudad de México, México
}

\begin{abstract}
Resumen
Introducción: El primer molar permanente (PMP) es susceptible de caries a partir de su erupción por su anatomía y porque ha estado expuesto antes que otros dientes. Métodos: Estudio observacional, prolectivo, transversal, comparativo, en 194 escolares con una media de edad de $9.9 \pm 1.8$ años. La valoración de la placa dentobacteriana (PDB) se realizó con el índice de O'Leary, y la experiencia de caries con los índices CPOS (suma de superficies dentales cariadas, perdidas/extraídas y obturadas) y CPOD (suma de dientes cariados, perdidos/extraídos y obturados). Resultados: La prevalencia de PDB en el PMP fue del 99.4\%, y la de caries, del 57.2\%. El valor del CPOD fue de $1.4 \pm 1.4$. La experiencia de caries por superficie dental en los niños de 7.10 años de edad fue de $2.2 \pm 2.3$ y son 7.9 veces más susceptibles a desarrollar lesiones (razón de momios: 8.9; intervalo de confianza al 95\%: 4.1-19.5; $p<0.0001$ ) que los menores de esa edad. Se detectó asociación con la variable edad y los valores de los índices de experiencia de caries; aun cuando estas son débiles en el caso del CPOS ( $r=0.439)$, el modelo permitió explicar el 19\% de la asociación, y el 22\% para el CPOD ( $r=0.464)$. Conclusiones: La caries dental se desarrolla rápidamente en los PMP. En general, no se le da la importancia debida porque se desconoce que se presenta en un diente permanente.
\end{abstract}

Palabras clave: Caries dental. Placa dentobacteriana. Primer molar permanente.

\section{Prevalence of plaque and dental decay in the first permanent molar in a school population of south Mexico City}

\begin{abstract}
Background: The first permanent molar is susceptible to acquire tooth decay since its eruption, due to its anatomy and because it has been exposed before other teeth. Method: An observational, prolective, transversal and comparative study in 194 students, with an average age of $9.9 \pm 1.8$ years. The evaluation of the dentobacterial plate (DBP) was analyzed using the O'Leary index and the tooth decay experience with the DMFS (sum of decayed, missing, extracted and filling dental surfaces) and DMFT (sum of decayed, missing, extracted and filling per tooth) indexes. Results: The prevalence of DBP in the first permanent molar was of $99.4 \%$ and tooth decay of $57.2 \%$. The value of DMFT was $1.4 \pm 1.4$. The tooth decay experience was higher in children from 7.10 years old with a value of $2.2 \pm 2.3$, who are 7.9 times more likely to develop lesions
\end{abstract}

\section{Correspondencia:}

*Olga Taboada Aranza

Fecha de recepción: 07-07-2017

Fecha de aceptación: 20-10-2017

DOI: 10.24875/BMHIM.M18000016
Disponible en internet: 13-04-2018 Bol Med Hosp Infant Mex. 2018;75:113-118 www.bmhim.com 
than younger children (odds ratio: $8.9 ; 95 \%$ confidence interval: $4.1-19.5 ; p<0.0001$ ). We found an association between age and the values of the tooth decay experience indexes; even though these were weak in the case of DMF $(r=0.439)$, the model allowed to explain $19 \%$ of the association, and $22 \%$ for DMFT $(r=0.464)$. Conclusions: Tooth decay develops rapidly in the first permanent molars; however, it does not receive the necessary care because it is usually unknown that it is a permanent tooth.

Key words: Tooth decay. Dentobacterial plaque. Permanent first molar.

\section{Introducción}

La caries es una enfermedad ampliamente extendida, que ha sido y sigue siendo el padecimiento crónico más frecuente en el mundo moderno. Se define como un proceso o padecimiento dinámico crónico que ocurre en la estructura dentaria en contacto con la acumulación de placa bacteriana, específicamente con los depósitos microbianos. Debido al desequilibrio entre la sustancia dental y el fluido de la placa, se da una pérdida mineral de la superficie dental, cuyo signo es la destrucción localizada de los tejidos duros ${ }^{1}$.

La Organización Mundial de la Salud señala que la caries dental sigue siendo considerada como una de las afecciones que mayormente compromete la salud bucal. El $98 \%$ de la población mundial padece caries dental y aproximadamente el $90 \%$ de los escolares de entre 5 y 17 años la tienen. En la literatura científica se reporta que la caries acusa un incremento mantenido con la edad, pues a los 7 años el valor del índice CPOD (suma de dientes cariados, perdidos/extraídos y obturados) es de 1.7 dientes con experiencia de caries, pero a los 14 años este valor aumenta a 7.4 dientes $^{2}$.

La caries se ha considerado como la enfermedad de mayor peso en la historia de la morbilidad bucal en todo el mundo. En la actualidad, su distribución y gravedad varían de una región a otra, y su aparición se asocia en gran medida con factores socioculturales, económicos, ambientales y del comportamiento ${ }^{3,4}$. Aunque su prevalencia ha disminuido, en los países industrializados afecta al $60-90 \%$ tanto de la población infantil como de la adulta 5 .

Las evidencias científicas muestran que la buena higiene bucal personal reduce la experiencia de caries dental. No obstante, existe poca evidencia para adjudicar el valor de la buena higiene bucal como un preventivo para la caries dental. Sin embargo, debido a la importancia de la presencia de placa dental en el desarrollo de la caries, la higiene bucal es la clave en el control de esta patología en los pacientes de alto riesgo. Los estudios han reportado la pérdida del primer molar permanente (PMP) en el $63.9 \%$ de los casos cuando se asocia con una higiene bucal deficiente ${ }^{6}$.
Esto significa que si por alguna razón la higiene bucal se hace difícil, quizás a causa de un impedimento o por la edad, el riesgo de caries dental aumenta.

La caries dental se desarrolla de forma rápida en los primeros molares permanentes, y puede evolucionar -en el transcurso de solo 6 meses- de una lesión incipiente a lesiones avanzadas con exposición franca de la cámara pulpar, por lo que la exodoncia de los molares afectados es frecuente. Los padres muchas veces desconocen que es un diente permanente, por lo que no dan la importancia necesaria a su cuidado debido a su poca motivación en el tema de la salud bucal. Lamentablemente, por esto ocurre la pérdida del PMP a muy temprana edad ${ }^{7}$.

La presencia del PMP es importante debido a que determina el patrón de masticación que el individuo tendrá durante su vida, además de tener un papel especial al realizar la mayor parte del trabajo de masticación y trituración de los alimentos. Este molar puede adquirir caries a partir de su erupción, alrededor de los 6 años de edad, ya sea por su anatomía o porque ha estado expuesto a la caries antes que otros dientes. Las posibles secuelas de la pérdida del PMP incluyen desde la migración mesial hasta la sobreerupción por la pérdida interoclusal, entre otras ${ }^{8}$.

EI PMP es una estructura dentaria que determina el desarrollo de una oclusión, pues al ocupar un gran espacio en el sector posterior, su presencia determina el equilibrio de la oclusión y la adecuada función masticatoria, y es de los primeros dientes permanentes que acompañan a la dentición primaria en la boca de un niño para transformarla en dentición mixta 9 .

En este contexto, se consideró necesario realizar una investigación que permitiera determinar la prevalencia de la placa dentobacteriana (PDB) y de la caries dental en el PMP, y evaluar la asociación de las variables sexo, edad y PDB como factores de riesgo para caries en una población escolar del sur de la Ciudad de México.

\section{Métodos}

Se realizó un estudio observacional, prolectivo, transversal y comparativo en una población conformada por 194 alumnos seleccionados a partir de un 
muestreo no probabilístico por conveniencia. Como criterio de inclusión se consideró que los escolares tuvieran por lo menos dos PMP y que presentaran el consentimiento informado del padre o tutor; el criterio de exclusión que se tomó en cuenta fue el deseo del escolar de no participar en el estudio, a pesar de contar con el consentimiento informado.

La investigación se inició con la calibración del diagnóstico clínico de caries dental, obteniéndose una confiabilidad de $\mathrm{k}=0.94$ (intervalo de confianza del $95 \%$ : 83-100). Posteriormente se procedió a la valoración clínica de la PDB con el índice de O'Leary (porcentaje de superficies dentales cubiertas de placa bacteriana), y de la caries dental con los índices CPOD y CPOS (suma de cariados, perdidos/extraídos y obturados, por unidad diente y por superficie, respectivamente).

La revisión clínica de la PDB y de la caries se realizó en un consultorio dental ubicado dentro de la escuela primaria. Para controlar un incremento de la PDB por una ingestión extra de alimentos durante el recreo, todos los niños fueron valorados antes de iniciar el descanso.

Los datos obtenidos se procesaron con el paquete estadístico SPSS 11.5, para lo cual se obtuvo la estadística descriptiva (frecuencias relativas) de las variables de estudio. La prueba de significación estadística para las variables cuantitativas fue la $t$ de Student, y para las cualitativas, la ji cuadrada, con un nivel de significancia del 95\%. Asimismo, se calculó la estimación del riesgo a caries dental a través de la razón de momios (RM). Para determinar la probable relación de las variables sexo, edad y PDB con la experiencia de caries dental en el PMP, se realizó un modelo de regresión lineal simple.

\section{Resultados}

La población de estudio estuvo conformada por 194 alumnos, seleccionados a partir de un muestreo no probabilístico por conveniencia, que asisten a la escuela primaria pública Anton Semionovich Makarenko, ubicada en la Delegación Coyoacán, al sur de la Ciudad de México. Tenían una media de edad de $9.0 \pm 1.8$ años (rango: 6-13). El 53\% (102) de los alumnos eran de sexo masculino y $47 \%$ (92) del femenino.

La prevalencia de PDB en el PMP fue del $99.4 \%$ para el total de alumnos. En la tabla 1 se observa que la proporción de alumnos con más del $20 \%$ de la superficie dental del PMP cubierta por PDB fue mayor para el sexo masculino y para los escolares con $>7.09$ años
Tabla 1. Distribución en frecuencia y porcentaje de la placa dentobacteriana por sexo y edad de los escolares

\begin{tabular}{l|c|c|}
\multirow{2}{*}{ Variable } & \multicolumn{2}{|c|}{ Placa dentobacteriana* } \\
\cline { 2 - 3 } & $\leq \mathbf{2 0 \%}$ & $>\mathbf{2 0 \%}$ \\
\hline $\begin{array}{c}\text { Sexo } \\
\text { Masculino }\end{array}$ & $11(10.8 \%)$ & $91(89.2 \%)$ \\
$\quad$ Femenino & $16(17.4 \%)$ & $76(82.6 \%)$ \\
Edad & $8(16.3 \%)$ & $41(83.7 \%)$ \\
$\leq 7.09^{\dagger}$ & $19(13.1 \%)$ & $126(86.9 \%)$ \\
$>7.09$ & $27(13.9 \%)$ & $167(86.1 \%)$ \\
Total &
\end{tabular}

*Riesgo para caries $>20 \%$ superficies cubiertas de placa dentobacteriana. †Percentil 25, no riesgo.

de edad. El valor del índice O'Leary para la población escolar fue del 48.1\% (IC 95\%: 46.3-49.7).

La prevalencia de caries del PMP en la población de estudio fue del $57.2 \%$. La experiencia de caries del PMP evaluada con el índice CPOD fue de $1.4 \pm 1.4$; la categoría más alta fue cariado con un valor de $1.2 \pm 1.3$. En el análisis por sexo, el valor más alto fue para el femenino $(1.5 \pm 1.4)$. El índice mayor por grupo de edad fue para los > 7.09 años, con un CPOD de $1.7 \pm 1.4$; esta diferencia resultó estadísticamente significativa con respecto a los de menor edad. Para los escolares con $>20 \%$ de superficies dentales cubiertas con PDB, el índice fue de $1.5 \pm 1.4$, con una diferencia estadísticamente significativa respecto de los que presentaron $\leq 20 \%$ de superficies con placa bacteriana (Tabla 2).

El valor del índice CPOS fue de $1.7 \pm 2.2$ con la categoría más alta de cariado y una media de $1.5 \pm 1.8$. En el análisis por sexo, el valor más alto fue para el femenino, de $1.8 \pm 2.3$. Por grupo de edad, el índice mayor de CPOS fue de $2.2 \pm 2.3$ para los escolares $>7.09$ años, con diferencias estadísticamente significativas respecto a los menores de esa edad. Para los alumnos con $>20 \%$ de superficies cubiertas con PDB, el índice fue de $1.8 \pm 2.3$ (Tabla 3).

De los factores de riesgo analizados, el tiempo de exposición medido a través de la edad mostró que los escolares con $>7.09$ años tienen 7.9 veces más riesgo de presentar caries en el PMP que los menores de esa edad, con una diferencia estadísticamente significativa (RM: 8.9; IC 95\%: 4.1-19.5; $p>0.0001$ ).

La presencia de PDB también resultó un factor de riesgo para presentar caries dental en el PMP, con un valor de 2.1 veces más en los escolares que presentan $>20 \%$ de superficies cubiertas de PDB (RM: 3.1 ; IC 95\%: 1.3-7.4; $p<0.01$ ) (Tabla 4). 
Tabla 2. Media y desviación estándar por categoría del índice CPOD del primer molar permanente según sexo, edad y superficies cubiertas de PDB de los escolares

\begin{tabular}{|c|c|c|c|c|c|}
\hline \multirow[t]{2}{*}{ Variable } & \multicolumn{5}{|c|}{ Índice } \\
\hline & Cariado & Obturado & Perdido & CPOD & Sano \\
\hline \multicolumn{6}{|l|}{ Sexo } \\
\hline Masculino & $1.2(1.3)$ & $0.1(0.4)$ & $0.0(0.0)$ & $1.3(1.4)$ & $2.7(1.4)$ \\
\hline Femenino & $1.3(1.3)$ & $0.1(0.6)$ & $0.0(0.1)$ & $1.5(1.4)$ & $2.4(1.4)$ \\
\hline \multicolumn{6}{|l|}{ Edad } \\
\hline$\leq 7.09^{*}$ & $0.3(0.7)$ & $0.0(0.0)$ & $0.0(0.0)$ & $0.3(0.7)$ & $3.4(1.0)$ \\
\hline$>7.09$ & $1.5(1.4)$ & $0.2(0.6)$ & $0.0(0.0)$ & $1.7(1.4)^{\ddagger}$ & $2.3(1.4)$ \\
\hline $\begin{array}{l}\text { Indice 0'Leary } \\
\leq 20 \%\end{array}$ & $0.8(1.3)$ & $0.0(0.0)$ & $0.0(0.0)$ & $0.8(1.3)$ & $3.0(1.3)$ \\
\hline$>20 \%^{\dagger}$ & $1.3(1.3)$ & $0.1(0.5)$ & $0.0(0.0)$ & $1.5(1.4)^{\S}$ & $2.5(1.4)$ \\
\hline Total & $1.2(1.3)$ & $0.1(0.5)$ & $0.0(0.0)$ & $1.4(1.4)$ & $2.6(1.4)$ \\
\hline
\end{tabular}

CPOD (suma de dientes cariados, perdidos/extraídos y obturados): índice de caries dental por unidad diente.

*Percentil 25, no riesgo.

${ }^{\dagger}$ Riesgo para caries, porcentaje de superficies cubiertas de placa dentobacteriana.

${ }_{\ddagger} \mathrm{p}<0.0001$, por prueba t de Student.

${ }^{\S} \mathrm{p}<0.04$.

Tabla 3. Media y desviación estándar por categoría del índice CPOS del primer molar permanente según sexo, edad y superficies cubiertas de placa dentobacteriana de los escolares

\begin{tabular}{|c|c|c|c|c|c|}
\hline \multirow[t]{2}{*}{ Variable } & \multicolumn{5}{|c|}{ Índice } \\
\hline & Cariado & Obturado & Perdido & CPOS & Sano \\
\hline \multicolumn{6}{|l|}{ Sexo } \\
\hline Masculino & $1.4(1.8)$ & $0.1(0.6)$ & $0.0(0.0)$ & $1.6(2.1)$ & $18.0(2.5)$ \\
\hline Femenino & $1.5(1.7)$ & $0.2(0.8)$ & $0.0(0.5)$ & $1.8(2.3)$ & $17.6(2.9)$ \\
\hline \multicolumn{6}{|l|}{ Edad } \\
\hline$\leq 7.09^{*}$ & $0.3(0.9)$ & $0.0(0.0)$ & $0.0(0.0)$ & $0.3(0.9)$ & $18.2(3.6)$ \\
\hline$>7.09$ & $1.9(1.8)$ & $0.0(0.4)$ & $0.2(0.8)$ & $2.2(2.3)^{\ddagger}$ & $17.7(2.3)$ \\
\hline$\leq 20 \%$ & $1.0(1.6)$ & $0.0(0.0)$ & $0.0(0.0)$ & $1.0(1.6)$ & $18.0(3.2)$ \\
\hline$>20 \%^{\dagger}$ & $1.6(1.8)$ & $0.0(0.3)$ & $0.2(0.8)$ & $1.8(2.3)$ & $17.8(2.6)$ \\
\hline Total & $1.5(1.8)$ & $0.2(0.7)$ & $0.0(0.3)$ & $1.7(2.2)$ & $17.8(2.7)$ \\
\hline
\end{tabular}

CPOS: índice de caries dental por superficie dental.

*Percentil 25, no riesgo.

${ }^{\text {t}}$ Riesgo para caries, porcentaje de superficies cubiertas de placa dentobacteriana.

${ }_{\ddagger} \mathrm{p}<0.0001$, por prueba t de Student.

Tabla 4. Factores de riesgo en los escolares para caries dental del primer molar permanente

\begin{tabular}{|l|c|c|c|}
\hline Variable & RM & IC 95\% & $\mathbf{p}^{*}$ \\
\hline $\begin{array}{l}\text { Edad > 7.09 años } \\
\text { > 20\% de superficies dentales }\end{array}$ & 8.9 & $4.1-19.5$ & 0.0001 \\
cubiertas con PDB & 3.1 & $1.3-7.4$ & 0.007 \\
Sexo masculino & 1.4 & $0.8-2.5$ & 0.205 \\
\hline
\end{tabular}

IC 95\%: intervalo de confianza al 95\%; PDB: placa dentobacteriana; RM: razón de momios, análisis univariado.

*Valor de p por ji al cuadrado.

En el análisis de regresión lineal simple (fig. 1) se encontró una asociación con la variable predictora edad y las variables de respuesta (índices CPOS y
CPOD). Aun cuando la asociación fue débil —según criterios de Colton-, el modelo permite explicar el 19\% de la asociación entre la edad y el CPOS $\left(r=0.43, p<0.0001 ; r^{2}=0.19, p<0.0001\right)$, y el $22 \%$ de la asociación con el CPOD $(r=0.46, p<0.0001$; $r^{2}=0.22, p<0.0001$ ).

\section{Discusión}

La caries es una de las enfermedades bucodentales de mayor prevalencia y la causa principal de pérdida de dientes. El PMP es el más susceptible a los ácidos producidos por las bacterias de la PDB debido a su aparición temprana en la cavidad bucal, su morfología y sus características funcionales. 


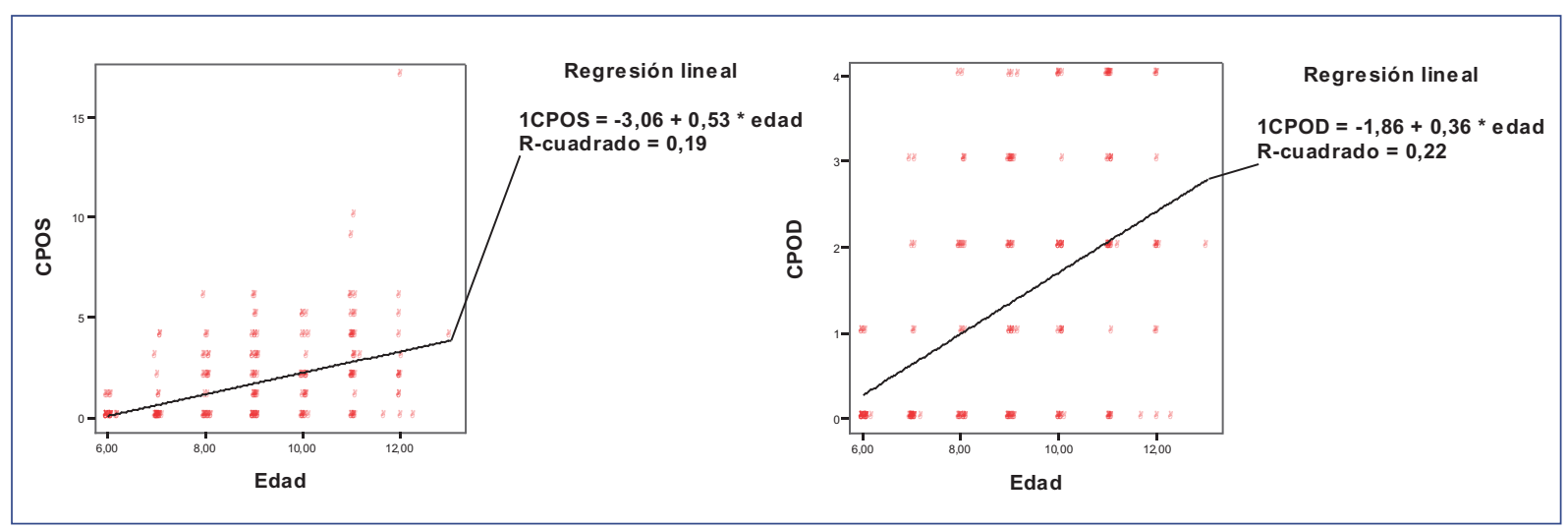

Figura 1. Regresión lineal de la variable predictora edad, como estimador del tiempo de exposición a factores de riesgo para caries dental en el primer molar permanente, y las variables de respuesta CPOS (suma de superficies dentales cariadas, perdidas/extraídas y obturadas) y CPOD (suma de dientes cariados, perdidos/extraídos y obturados).

Diversos estudios muestran que la prevalencia de caries se encuentra en un rango del $60-90 \%$. Con respecto a la prevalencia de caries en el PMP, un estudio realizado en la Delegación Tláhuac, Ciudad de México, mostró una prevalencia del $58.6 \%$, valor un poco más alto que el encontrado en el presente estudio (57.2\%). El sexo femenino presentó mayor número de PMP con caries dental, dato semejante al reportado en este estudio ${ }^{10}$.

En un estudio realizado en Chile, Zaror, et al. ${ }^{11}$ repotaron una prevalencia de caries en el PMP del $68 \%$, mayor que lo reportado por nosotros. En otro estudio realizado en Cuba por Quesada, et al. ${ }^{12}$ se reportó una prevalencia del $57.6 \%$ de caries en el PMP en menores de sexo femenino, dato semejante al aquí reportado; los autores señalaron que el grupo de edad en que se encontró una mayor afectación fue en el de 12 a 14 años, similar a lo que se halló en este estudio. Llama la atención el estudio realizado por Rodríguez, et al. ${ }^{13}$, también en población cubana, en el cual, a diferencia de nuestro estudio, se reportó una prevalencia de caries en el PMP del $52.4 \%$ en el sexo masculino y una alta prevalencia de PDB utilizando el índice Green Vermillón modificado, y se observó una higiene bucal regular en el $80.7 \%$ del sexo masculino y en el $80.1 \%$ del femenino.

En un estudio que valoró la higiene bucal con el índice de higiene oral simplificado en escolares, se reportó una buena higiene dental en el $51.1 \%^{14}$. Debido al tipo de índice utilizado, no se hace referencia a este estudio, aunque llama la atención por la baja prevalencia de placa dental.

En Venezuela se realizó un estudio de prevalencia de PDB en el que se reportó un índice de O'Leary del $43.1 \%$ en niños en edad escolar, concordando con los resultados de este estudio, en el que la alta prevalencia de PDB es un factor de riesgo para presentar caries dental ${ }^{15}$.

Un estudio realizado por Discacciate y Lértora ${ }^{16}$, en Argentina, mostró que la prevalencia de caries del PMP fue del $52 \%$, y mayor en la población de 7 años (58.3\%), dato que concuerda con los resultados del presente estudio.

Otro estudio realizado en Venezuela reportó que el grupo de edad con mayores afecciones en el PMP fue el de la primera década de la vida, con una prevalencia del $70 \%$, dato semejante al reportado en la presente investigación ${ }^{9}$.

Moreno, et al. ${ }^{17}$ realizaron un estudio en el que reportaron una alta prevalencia de caries en escolares de las escuelas oficiales de la Ciudad de México ${ }^{17}$.

En contraste, los resultados de Meneses, et al. ${ }^{18} \mathrm{di}-$ firieron con esta investigación, ya que la prevalencia de caries en el PMP fue de solo el $20.3 \%$ en una población de escolares de la ciudad de Medellín.

La PDB tiene el papel más importante en la aparición de la caries; sin embargo, no es el único elemento que interviene para su desarrollo, debido a que no todas las colonias formadoras de bacterias dentro de la biopelícula son afines a los tejidos dentales. La caries está asociada con múltiples factores de riesgo biológicos, sistémicos y socioeconómicos, cuya combinación puede variar el curso y la agresividad de la enfermedad, por lo que es necesario buscar y analizar otros factores de riesgo.

\section{Responsabilidades éticas}

Protección de personas y animales. Los autores declaran que para esta investigación no se han realizado experimentos en seres humanos ni en animales. 
Confidencialidad de los datos. Los autores declaran que en este artículo no aparecen datos de pacientes. Derecho a la privacidad y consentimiento informado. Los autores han obtenido el consentimiento informado de los pacientes y/o sujetos referidos en el artículo. Este documento obra en poder del autor de correspondencia.

\section{Conflicto de intereses}

Los autores declaran no tener ningún conflicto de intereses.

\section{Bibliografía}

1. González BY, Sexto DN, Francisco LA, Vázquez DA. Comportamiento de la caries dental en el primer molar permanente en escolares. Medisur. 2009;7:4. Disponible en: http://www.medisur.sld.cu/index.php/medisur/ article/view/587.

2. Carrero G. Fleitas A, Arellano L. Prevención de caries dental en primeros molares permanentes utilizando sellantes de fosas y fisuras y enjuagues bucales fluorados. Rev Odont Andes. 2006;1:44-53.

3. Cid RM, Álvarez AM, Alfonso PC, Montes de Oca RR. Influencia de los determinantes sociales en la salud del primer molar permanente. Rev Med Electrón. 2017;39:158-69.

4. Sales-Peres SH, Bastos JR. An epidemiological profile of dental caries in 12-year-old children residing in cities with and without fluoridated water supply in the central western area of the State of São Paulo, Brazil. Cad Saúde Pública. 2002;18:1281-8.

5. Tascón J, Aranzazu L, Velasco T, Trujillo K, Paz M. Primer molar permanente: historia de caries en un grupo de niños entre los 5 y 11 años frente a los conocimientos, actitudes y prácticas de sus madres. Rev Colomb Med. 2006;36:41-6.
6. Sánchez MD, Pons LY, Betancourt GA, Santateresa MA. Pérdida del primer molar permanente: factores de riesgo y salud bucodental en adolescentes. Rev Finlay. 2017;7:17-25.

7. Guerra M, Rodríguez C, Carrasco W, Tovar V, López L. Prevalencia de caries en el primer molar permanente en niños VIH (+) vs VIH (-). Acta Odontol Venez. 2012;51:9.

8. Casanova RA, Medina SC, Casanova RJ, Vallejos SA, Maupomé G, Kageyama EM. Factores asociados a la pérdida del primer molar permanente en escolares de Campeche, México. Acta Odontol Venez. 2005;43:268-75.

9. Bermúdez S, González AV, Márquez JD, Restuccia G, Kammann MA Zambrano $\mathrm{O}$, et al. Prevalencia de caries y tratamientos realizados en el primer molar permanente en la población de Río Chico. Estado Miranda, Venezuela. Acta Odontol Venez. 2013;51:9.

10. Oropeza OA, Molina FN, Castañeda CE, Zaragoza RY, Cruz LD. Caries dental en primeros molares permanentes de escolares de la delegación Tláhuac. ADM. 2012;69:63-8.

11. Zaror SC, Pineda TP, Villegas VM. Estudio clínico del primer molar permanente en niños de 6 años de edad de la Comuna de Calbuco, Chile. Acta Odontol Venez. 2012;49:8.

12. Quesada AC, Hernández GM, Carbó AJ, Quesada AL. Urgencia estomatológica por caries en los primeros molares permanentes en menores de 15 años. Medicentro. 2010;4:12-24.

13. Rodríguez OF, Mursulí SM, Pérez GL, Martínez RM. Estado de salud del primer molar permanente en niños de 6-11 años. Sancti Spíritus. 2011. Gac Med Espirit. 2013;15:37-47.

14. Murrieta PF, Juárez LL, Linares VC, Zurita MV. Prevalencia de gingivitis en un grupo de escolares y su relación con el grado de higiene oral y el nivel de conocimientos sobre salud bucal demostrado por sus madres. Bol Med Hosp Infant Mex. 2004;61:44-54.

15. Agreda M, Hernández M, Salinas P, Acevedo J, Acostai G, Chacón C, et al. Presencia de placa dental en alumnos de quinto grado de la Escuela Básica "Eloy Paredes". Mérida, Venezuela. MedULA. 2008;17:95-9.

16. Discacciate de LM, Lértora M. Primer molar permanente: riesgo y afecciones en sus primeros años. Universidad Nacional del Nordeste, Comunicaciones científicas y tecnológicas. Cátedra de Odontopediatría, Facultad de odontología; 2004. Disponible en: http://www.unne.edu.ar/ unnevieja/Web/cyt/com2004/3-Medicina/M-030.pdf

17. Moreno AA, Carreón GJ, Alvear GG, López MS, Vega FL. Riesgo de caries en escolares de escuelas oficiales de la Ciudad de México. Rev Mex Ped. 2001;68:228-33.

18. Meneses-Gómez E, Vivares-Builes A, Botero-Botero A. Condición del primer molar permanente en una población de escolares de la ciudad de Medellín 2012. CES Odontol. 2013;26:24-32. 